OPEN ACCESS

Edited by:

Xihui Shen,

Northwest A\&F University, China

Reviewed by: Arumugam Kamaladevi, Alagappa University, India

Alexander Van Parys,

Ghent University, Belgium

${ }^{*}$ Correspondence:

Joshua Gong

joshua.gong@canada.ca

Mingyong Xie

myxie@ncu.edu.cn

Specialty section:

This article was submitted to

Bacteria and Host

a section of the journal

Frontiers in Cellular and Infection

Microbiology

Received: 23 April 2020

Accepted: 20 August 2020

Published: 29 September 2020

Citation:

Liu X, Jiang L, Li L, Yu H, Nie S, Xie M and Gong J (2020) The Role of Neurotransmitters in the Protection of

Caenorhabditis Elegans for Salmonella Infection by Lactobacillus.

Front. Cell. Infect. Microbiol. 10:554052.

doi: 10.3389/fcimb.2020.554052

\section{The Role of Neurotransmitters in the Protection of Caenorhabditis Elegans for Salmonella Infection by Lactobacillus}

\author{
Xiaozhen Liu ${ }^{1,2,3}$, Leming Jiang ${ }^{2,3}$, Linyan $\mathrm{Li}^{2,3}, \mathrm{Hai} \mathrm{Yu}^{2}$, Shaoping $\mathrm{Nie}^{3}$, Mingyong $\mathrm{Xie}^{3,4 *}$ \\ and Joshua Gong ${ }^{2 *}$ \\ ${ }^{1}$ Engineering Research Center of Health Food Design \& Nutrition Regulation, School of Chemical Engineering and Energy \\ Technology, Dongguan University of Technology, Dongguan, China, ${ }^{2}$ Guelph Research and Development Center, Agriculture \\ and Agri-Food Canada, Guelph, ON, Canada, ${ }^{3}$ State Key Laboratory of Food Science and Technology, Nanchang University, \\ Nanchang, China, ${ }^{4}$ National R\&D Center for Freshwater Fish Processing, Jiangxi Normal University, Nanchang, China
}

Salmonellosis is a common foodborne disease. We previously reported the protection of Caenorhabditis elegans from Salmonella Typhimurium DT104 infection by Lactobacillus zeae LB1. However, the mechanism is not fully understood. C. elegans exhibits behavior plasticity when presented with diverse pathogenic or commensal bacteria. Whether it can exert approach avoidance to $S$. Typhimurium through altering its neurological activity remains to be determined. In the current study, both the wild type and mutants defective in serotonin or dopamine production of $C$. elegans were used to investigate olfactory preference of the nematode to L. zeae LB1, DT104, and Escherichia coli OP50 by choice assays, and its resistance to DT104 infection and the protection offered by L. zeae LB1 using a life-span assay. The expression of target genes in $C$. elegans was also examined by real-time quantitative PCR. Results showed that pre-exposure to L. zeae LB1 did not elicit aversive olfactory behavior of the nematode toward DT104. Both mutants tph-1 and cat-2 succumbed faster than the wild type when infected with DT104. While pre-exposure to $L$. zeae LB1 significantly increased the survival of both the wild type and mutant tph-1, it provided no protection to mutant cat-2. Supplementation of dopamine resulted in both the resistance of mutant cat-2 to $S$. Typhimurium infection and the protection from L. zeae LB1 to the same mutant. Gene expression data also supported the observations in the life-span assay. These results suggest that both serotonin and dopamine play a positive role in the host defense of $C$. elegans to $S$. Typhimurium infection and that the L. zeae LB1 protection is not dependent on modifying olfactory preference of the nematode but mediated by dopamine that may have involved the regulation of p38-mitogen-activated protein kinase and insulin/insulin-like growth factor signaling pathways.

Keywords: neurotransmitters, Caenorhabditis elegans, Salmonella Typhimurium, Lactobacillus, olfactory behavior 


\section{INTRODUCTION}

Salmonellosis is one of the most common foodborne diseases, and its control still remains a challenge worldwide (Wei et al., 2019). Probiotics have long been used to control Salmonella enteritidis infection (Chambers and Gong, 2011; Forkus et al., 2017; Gut et al., 2018; Lai and Huang, 2019). However, their molecular mechanisms, including the roles of neurotransmitters in the host defense to $S$. enteritidis infection and probiotic protection, are not fully understood. Host-pathogen interaction is a dynamic process that includes not only the relationship between the host and pathogen but also their persistence during pathogenesis. The host innate immune response represents the first line of defense against pathogens' attack.

Caenorhabditis elegans is a laboratory animal, a good model to study the host-microbe interactions, including elucidations of their molecular mechanisms (Kaletta and Hengartner, 2006). Studies from C. elegans and other diverse organisms have revealed that key innate immune signaling regulators are strongly conserved (Irazoqui et al., 2010; Visvikis et al., 2014; Cohen and Troemel, 2015). The highly conserved mitogen-activated protein kinase (MAPK) signaling pathway that activates the innate immune response to bacterial infection is particularly important for exploring the role of innate immunity in organismal stress resistance and the regulation of longevity (Ermolaeva and Schumacher, 2014). Apart from the immunologic strategy to resist bacterial infection, C. elegans can also utilize its nervous system to respond to diverse microbial cues and to engage in a protective behavioral avoidance response to environmental pathogens (Meisel and Kim, 2014). Zhang et al. (2005) reported that C. elegans modified its olfactory preferences after an exposure to pathogenic bacteria. The nematode could avoid the odor from a pathogen and increase its attraction to the odor from familiar non-pathogenic bacteria. The increase of serotonin in $\mathrm{ADF}$ chemosensory neurons was shown to promote such aversive learning. In addition to the serotonin system, the dopamine system plays a critical role in motor control, reward, and cognition in vertebrate central nervous system (Schultz, 2016). Dysfunction of the dopamine system is associated with various disorders, including Parkinson's disease, schizophrenia, Tourette's syndrome, attention deficit hyperactivity disorder, and addictions (Sanyal et al., 2004). The dopamine-modulated behaviors are subject to behavioral plasticity in C. elegans. Qin and Wheeler (2007) have revealed that dopamine mediates C. elegans exploratory behavior and that the wild-type (WT) worms are significantly more likely than dopamine defective mutants to learn to make conditioned responses linking reward to location. However, little is known about the approach avoidance of C. elegans to Salmonella Typhimurium through altering the neurobehavior that is mediated by neurotransmitters.

Dopamine signaling in C. elegans has been shown to negatively regulate the innate immune response through a D1-like dopamine receptor, DOP-4, by down-regulating the p38/PMK1 MAPK pathway, thus making the nematode more susceptible to Pseudomonas aeruginosa infection (Cao and Aballay, 2016). Similarly, serotonin signaling in C. elegans suppressed its innate immune response and limited the rate of pathogen clearance of Microbacterium nematophilum through regulating G-protein signaling (Anderson et al., 2013). It has been reported that conditioning of C. elegans with Lactobacillus acidophilus NCFM enhanced the Gram-positive immune responses of the nematode by activating both the p38 MAPK and the $\beta$-catenin signaling pathways (Kim and Mylonakis, 2012). Ikeda et al. (2007) also found that feeding nematodes with bifidobacteria or lactobacilli not only prolonged the life span of worms but also improved their resistance to the infection of $S$. enteritidis. Recently, we identified several Lactobacillus isolates that were able to protect $C$. elegans from death caused by $S$. Typhimurium or Escherichia coli infection (Wang et al., 2011; Zhou et al., 2014). Lactobacillus zeae LB1 was one of the best potential probiotic bacteria. It provided the protection by inhibiting the gene expression of E. coli enterotoxins (Zhou et al., 2014) and also by regulating C. elegans cell signaling through the p38-MAPK and DAF/insulin/insulinlike growth factor (IGF) pathways to control the production of antimicrobial peptides and defensing molecules (Zhou et al., 2018). However, it is unknown if the olfactory preference and neurotransmitters such as serotonin and dopamine play a role in the protection offered by the Lactobacillus isolate. The current study therefore wanted to address the questions.

\section{MATERIALS AND METHODS \\ Caenorhabditis elegans and Bacterial Cultures}

Caenorhabditis elegans N2 Bristol WT, mutant cat-2 (e1112, defective in dopamine production), and mutant tph-1 ( $m g 280$, defective in serotonin production) were obtained from Caenorhabditis Genetics Center (CGC, University of Minnesota, Minneapolis) and cultivated as described (Julia et al., 2007). Briefly, worm embryos were collected by bleaching and were grown at $22^{\circ} \mathrm{C}$. Worms were cultivated at $22^{\circ} \mathrm{C}$ on nematode growth medium (NGM) agar seeded with Escherichia coli OP50 (Stiernagle, 1999).

Escherichia coli OP50 grown in Luria-Bertani broth at $37^{\circ} \mathrm{C}$ for $12 \mathrm{~h}$ with a cell density of $10^{8}$ colony-forming unit (CFU) per milliliter was used as food for the nematode. Salmonella enterica serovar Typhimurium DT104 strain SA970934 is a porcine multiantibiotic-resistant isolate (Poppe et al., 1998, 2002). It was cultured on tryptic soy broth (TSB) or tryptic soy agar at $37^{\circ} \mathrm{C}$ for $16 \mathrm{~h}$. Following three washes with $\mathrm{S}$ basal buffer containing $5.85 \mathrm{~g}$ of $\mathrm{NaCl}, 1 \mathrm{~g}$ of $\mathrm{K}_{2} \mathrm{HPO}_{4}, 6 \mathrm{~g}$ of $\mathrm{KH}_{2} \mathrm{PO}_{4}$, and $1 \mathrm{ml}$ of cholesterol ( 5 $\mathrm{mg} / \mathrm{ml}$ in ethanol) in $1 \mathrm{~L}$ of the solution, a concentration of $10^{8}$ $\mathrm{CFU} / \mathrm{ml}$ of cell suspension of the pathogen was used in assays. Lactobacillus zeae LB1 was cultured in de Man Rogosa Sharpe (MRS) broth or agar at $37^{\circ} \mathrm{C}$ for $18 \mathrm{~h}$ in an anaerobic chamber (Coy Laboratory Products, Grass Lake, MI) with an atmosphere of $85 \% \mathrm{~N}_{2}, 10 \% \mathrm{CO}_{2}$, and $5 \% \mathrm{H}_{2}$ (Wang et al., 2011). After three washes with $\mathrm{S}$ basal buffer, a concentration of $1 \times 10^{9} \mathrm{CFU} / \mathrm{ml}$ of cell suspension of the isolate was used in assays.

\section{Free-Choice and Two-Choice Behavior Assays}

L4 stage (Stiernagle, 1999) worms were grown on a NGM plate that was evenly spread with $200 \mu \mathrm{l}$ of E. coli OP50 suspension. The free-choice or two-choice olfactory preference assay was 
based on standard chemotaxis assays (Bargmann et al., 1993) except that bacterial suspensions were used as odor sources. In the free-choice assay, $50 \mu \mathrm{l}$ of each bacterial culture (L. zeae LB1, DT104, and OP50) was spotted onto one side of a new NGM plate and air-dried for $30 \mathrm{~min}$ at $25^{\circ} \mathrm{C}$. Worms at L4 stage (50-100 worms) that had been washed twice in $\mathrm{S}$ basal buffer were then placed at the center of the plate, equidistant from the tested bacterial spots. The nematode was allowed to move freely for $1-2 \mathrm{~h}$ before being immobilized by $1 \mathrm{ml}$ of $10 \mathrm{mM}$ sodium azide applied at the bacterial spots. In most assays, worms quickly entered one bacterial lawn and remained there for the duration of the assay. A two-choice behavior assay was also conducted as indicated in Figures 1A-F. For pretreatment of C. elegans, $200 \mu \mathrm{l}$ of L. zeae LB1 culture was spread on a plate, and the nematode was kept on the plate for $2 \mathrm{~h}$ at $25^{\circ} \mathrm{C}$ prior to the two-choice behavior assay. Each treatment was repeated three times. Choice index of $\mathrm{A}$ against $\mathrm{B}=$ (number of worms in the lawn of bacterium A - number of worms in the lawn of bacterium B)/total worm number. If choice index = -1.0 represents complete preference for bacterium $B$, then +1.0 represents complete preference for bacterium A, 0.0 represents an equal distribution (Julia et al., 2007; Kamaladevi et al., 2016).

\section{Life-Span Assay of Caenorhabditis elegans}

The life-span assays of $C$. elegans were performed as described with slight modifications (Zhou et al., 2018). Synchronized $C$. elegans was transferred to NGM agar with E. coli OP50 at $25^{\circ} \mathrm{C}$ until it reached the L4 stage. In the assay, there were three types of treatment: (1) control, (2) DT104 infection only, and (3) L. zeae LB1 pretreatment. In the control, the nematode was treated with E. coli OP50 only throughout the entire assay. In the DT104 infection only, the L4 stage nematode was incubated with E. coli OP50 for $18 \mathrm{~h}$ followed by incubation with $200 \mu \mathrm{l}$ of DT104 for up to 7 days in the absence of E. coli OP50. In the $L$. zeae LB1 pretreatment, the nematode was incubated with $200 \mu \mathrm{l}$ of $L$. zeae LB1 for $18 \mathrm{~h}$ followed by incubation with 200 $\mu \mathrm{l}$ of DT104 for up to 7 days in the absence of E. coli OP50. The incubation temperature was $25^{\circ} \mathrm{C}$. Each assay was started by transferring L4 stage worms (25 worms per replicate and three replicates per treatment) onto the agar plates seeded with either E. coli OP50 or L. zeae LB1, which was designated as day 0. After $18 \mathrm{~h}$ of incubation, worms on each plate within each treatment (either DT104 infection only or L. zeae LB1 pretreatment) were transferred to a fresh NGM plate daily that had been seeded with DT104 and was subsequently incubated at $25^{\circ} \mathrm{C}$. The control group was processed in parallel, in which worms were transferred to a fresh NGM plate daily that had been seeded with E. coli OP50. The survival of nematode was examined at 24-h intervals for up to 7 days. To determine the survival of C. elegans, the number of live worms was recorded daily and calculated as follows: survival rate $(\%)=($ live worms/total worms used $) \times 100$. A worm was considered to be dead when it failed to respond to touch with a platinum loop; each treatment was repeated three times.

\section{RNA Extraction and Quantitative PCR Analysis}

Fresh worms were washed three times with RNase-free water and lysed using the proteinase K-based method (Jiang et al., 2019) before RNA extraction with TRIzol ${ }^{\mathrm{TM}}$ Reagent (Invitrogen, Cat. \# 15596026). After RNA extraction, the samples were treated with DNase I (Ambion, TX) at $37^{\circ} \mathrm{C}$ for $30 \mathrm{~min}$ and then verified as DNA-free by PCR assays. RNA integrity was determined by visualization in an agarose gel. The RNA concentration was determined with a NanoDrop ND-1000 spectrophotometer (NanoDrop Technologies, Wilmington, DE) after removing DNA contaminations.

Gene expression levels were determined by quantitative PCR (QPCR) analysis, following reverse transcription using $\mathrm{qS}$ cript ${ }^{\mathrm{TM}}$ cDNA SuperMix (Quantabio, Cat. \# 95048-100) according to manufacturer's protocol; 1-2 $\mu$ l of cDNA template was used for a QPCR assay. Two housekeeping genes, gapdh and $r p l-4$, were used as references. QPCR assays were performed using a AB7500 Real Time PCR System (Applied Biosystems Inc., Foster City, CA) with iTaq ${ }^{\mathrm{TM}}$ Universal SYBR Green Supermix (Bio-Rad, Cat. \# 172-5122) under the conditions as follows: $95^{\circ} \mathrm{C}$ for $3 \mathrm{~min}$ followed by 40 cycles of denaturing at $95^{\circ} \mathrm{C}$ for $30 \mathrm{~s}$, annealing at $56^{\circ} \mathrm{C}$ for $1 \mathrm{~min}$, and extension at $72^{\circ} \mathrm{C}$ for $30 \mathrm{~s}$. The PCR primers are listed in Table $\mathbf{1 .}$

The fold changes of target genes were determined using the $2^{-\Delta \Delta \mathrm{Ct}}$ method (Livak and Schmittgen, 2001). The $\Delta \mathrm{Ct}$ represents the difference between the $\mathrm{Ct}$ value with the primers to a target gene and the $\mathrm{Ct}$ value to the housekeeping genes. The $\Delta \Delta \mathrm{Ct}$ represents the difference between the $\Delta \mathrm{Ct}$ value of mutant cat-2 group in either the presence or absence of dopamine and the $\Delta \mathrm{Ct}$ value of WT (N2) control group within the same treatment. The WT groups had the $2^{-\Delta \Delta \mathrm{Ct}}$ value of 1 .

\section{Functional Restoring Experiments}

Previous studies have shown that exogenous dopamine added to experimental plates or buffers can mimic the effects of a dopaminergic signaling, although a relatively high concentration is required to elicit a response in the assay due to the low permeability of cuticle to dopamine (Sanyal et al., 2004; Ezak and Ferkey, 2010; Ezcurra et al., 2011). In the current study, dopamine hydrochloride (Sigma-Aldrich, CAS: 62-31-7) solution was sterilized through $0.22-\mu \mathrm{m}$ membrane filters and included freshly in NGM agar at $0,0.25,0.5,0.75$, and $1.5 \mathrm{mM}$. Synchronized L1 stage worms of mutant cat-2 were cultured on NGM agar containing dopamine and seeded with OP50 until they reached L4 stage. In the life-span assay, the entire procedure of the mutant, including L. zeae LB1 pretreatment, DT104 infection, and subsequent observation, was conducted in the presence of dopamine. The WT was treated in parallel without exposure to dopamine to serve as a reference.

\section{Statistical Analysis}

All statistical computation analyses were performed using Statistical Product and Service Solutions (SPSS, Windows version 11.5). Survival curves of $C$. elegans were compared using the Kaplan-Meier survival analysis followed by a log-rank test. One-way analysis of variance and the Tukey multiple comparisons were carried out to test for significant differences between the means. Means with $P \leq 0.05$ were considered to differ significantly, and $P \leq 0.01$ were considered to be extremely different. 

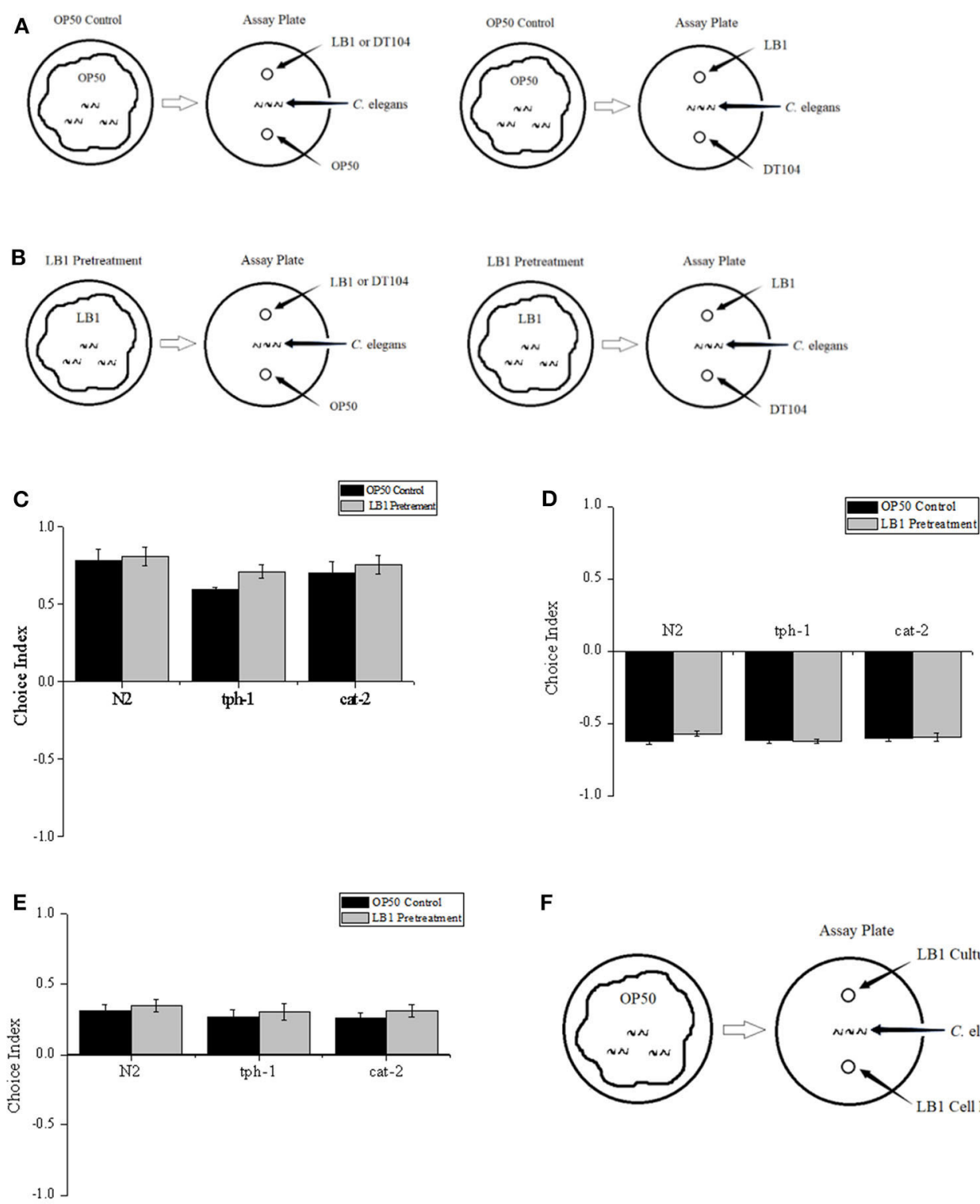

F
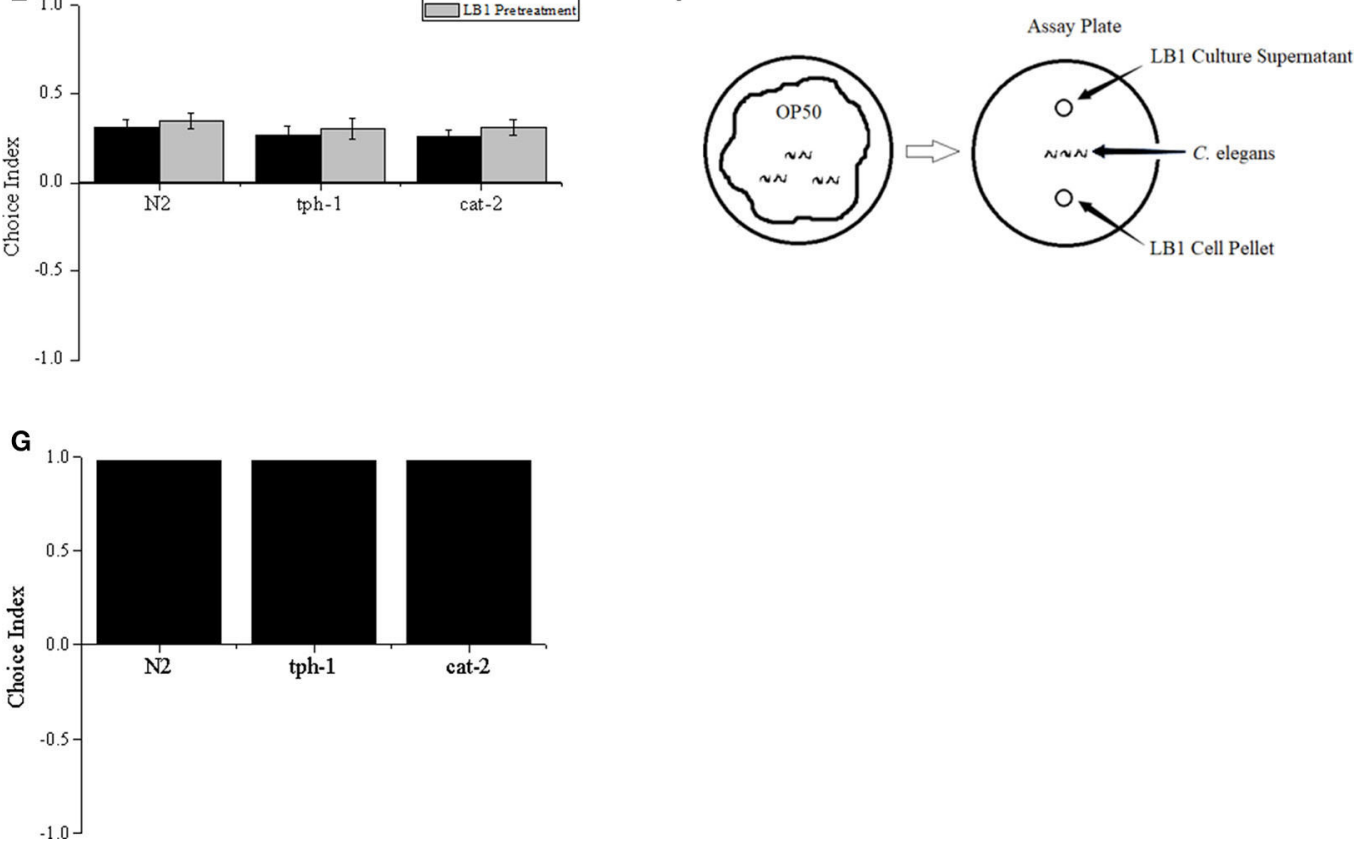

FIGURE 1 | Two-choice behavior assay of Caenorhabditis elegans. L4 stage worms including the wild type (WT) (N2), mutant tph-1, and mutant cat-2 were treated with Escherichia coli OP50 or Lactobacillus zeae LB1, and positioned in the middle of the assay plate, and exposed to test bacteria with equal distance; then choice index was calculated. (A) Worms were treated with OP50 only (OP50 control). (B) Worms were pretreated with L. zeae LB1. (C) Choice index of L. zeae LB1 against OP50. (D) Choice index of DT104 against $L$. zeae LB1. (E) Choice index of DT104 against OP50. (F) $L 4$ stage worms were positioned in the middle of the plate and exposed to L. zeae LB1 cells or L. zeae LB1 culture supernatant with equal distance. (G) Choice index of L. zeae LB1 culture supernatant against L. zeae LB1 cells. Choice index of $A$ against $B=$ (number of worms in the lawn of bacterium $A$ - number of worms in the lawn of bacterium B)/total worm number. Results are presented as mean \pm S.D. with triplicate measurement. 
TABLE 1 | Primer of QPCR assay.

\begin{tabular}{|c|c|c|c|}
\hline Primer & $\begin{array}{l}\text { Amplicon } \\
\text { (bp) }\end{array}$ & Sequence $\left(5^{\prime}-3^{\prime}\right)$ & $\begin{array}{l}\text { Source } \\
\text { (reference) }\end{array}$ \\
\hline Rpl-4-F & 182 & TTGCCCGTATTCCACGTGTT & This study \\
\hline Rpl-4-R & & GGATTCCGGAGGCAGCAATA & \\
\hline Gapdh-F & 158 & ACTCGACCCACGGTCAATTC & This study \\
\hline Gapdh-R & & ACTCGACAACGAAATCGGCT & \\
\hline Daf-16-F & 181 & TCGTCTCGTGTITCTCCAGC & Zhou et al., 2018 \\
\hline Daf-16-R & & TAATCGGCTTCGACTCCTGC & \\
\hline Age-1-F & 359 & СTCCTGAACCGACTGCCAAT & Zhou et al., 2018 \\
\hline Age-1-R & & AAATGCGAGTTCGGAGAGCA & \\
\hline Lys-7-F & 153 & GTACAGCGGTGGAGTCACTG & Zhou et al., 2018 \\
\hline Lys-7-R & & GCCTTGAGCACATTTCCAGC & \\
\hline Clec-60-F & 219 & CGGTTCAATGCGGTATGGC & Zhou et al., 2018 \\
\hline Clec-60-R & & TGAAGCTGTGGTTGAGGCAT & \\
\hline Clec-85-F & 121 & CCAATGGGATGACGGAACCA & Zhou et al., 2018 \\
\hline Clec-85-R & & CTTCTGTCCAGCCAACGTCT & \\
\hline Abf-3-F & 189 & AACAGATTGGGGTCAGCTCG & Zhou et al., 2018 \\
\hline Abf-3-R & & TGGAGACCATTATTGCCGGG & \\
\hline Abf-2-F & 176 & CCGTTCCCTITCCTTGCAC & Zhou et al., 2018 \\
\hline Abf-2-R & & GACGACCGCTTCGTTCTTG & \\
\hline Tir-1-F & 223 & TTGGGTGCACAAAGAGCTGA & Zhou et al., 2018 \\
\hline Tir-1-R & & GGTCGGTGTCGTTCTGTTCA & \\
\hline Nsy-1-F & 122 & AGCGGCTCGATCAACAAGAA & Zhou et al., 2018 \\
\hline Nsy-1-R & & CCCATTCCACCGATATGCGA & \\
\hline Sek-1-F & 158 & CACTGTTGGCGACGATGAG & Zhou et al., 2018 \\
\hline Sek-1-R & & ATTCCGTCCACGTTGCTGAT & \\
\hline Pmk-1-F & 115 & CCAAAAATGACTCGCCGTGA & Zhou et al., 2018 \\
\hline Pmk-1-R & & CTITGCAGTTGGACGACGA & \\
\hline Skn-1-F & 153 & CTGGCATCCTCTACCACCAC & Zhou et al., 2018 \\
\hline Skn-1-R & & TTGGTGATGATGGCCGTGTT & \\
\hline Dbl-1-F & 194 & TाTGCGGCGAACAAATCGT & Zhou et al., 2018 \\
\hline Dbl-1-R & & TTCGCTGTTGCCTGTTGTG & \\
\hline Spp-1-F & 106 & TGGACTATGCTGTTGCCGTT & Zhou et al., 2018 \\
\hline Spp-1-R & & ACGCCTTGTCTGGAGAATCC & \\
\hline Jnk-F & 102 & TCACAACACTCTGCTCGCAT & Zhou et al., 2018 \\
\hline Jnk-R & & TGGAACCAGCCAATTCCCAA & \\
\hline Sod-3-F & 73 & AAATGTCCGCCCAGACTATG & Zhou et al., 2018 \\
\hline Sod-3-R & & TGGCAAATCTCTCGCTGA & \\
\hline Ced-3-F & 166 & AGAAGGAGCTTGCTAGAGAGGA & Zhou et al., 2018 \\
\hline Ced-3-R & & ACTGCTTCACGATCTCCCG & \\
\hline
\end{tabular}

\section{RESULTS}

\section{Olfactory Preference of Caenorhabditis elegans}

The preference of Caenorhabditis elegans to different bacterial odor was firstly investigated in a free-choice assay. C. elegans was significantly attracted to Lactobacillus zeae LB1 $(P \leq 0.05)$, but not to other bacteria. Approximately $92 \%$ worms moved to $L$. zeae $\mathrm{LB} 1,5 \%$ to DT104, and 3\% to OP50 in the assay.

To determine whether pretreatment with L. zeae LB1 can alter the preference of C. elegans toward DT104, binary choice assays without (Figure 1A) or with (Figure 1B) L. zeae LB1 pretreatment were conducted. Although most worms were attracted to L. zeae LB1 in the assay, the L. zeae LB1 pretreatment did not change the olfactory behavior of $C$. elegans. The choice indexes in each pair of the test were similar regardless if the nematode had been treated with $L$. zeae LB1 or not, in which the choice indexes were 0.81 and 0.78 for the pair of L. zeae LB1 vs. OP 50 with or without L. zeae LB1 pretreatment (Figure 1C), -0.57 and -0.62 for the pair of DT104 vs. L. zeae LB1 with or without L. zeae LB1 pretreatment (Figure 1D), and 0.35 and 0.31 for the pair of DT104 vs. OP50 with or without $L$. zeae LB1 pretreatment (Figure 1E). The olfactory behavior of $C$. elegans mutants defective in serotonin ( $t p h-1)$ or dopamine (cat2) was also investigated in the two-choice assay. Both mutants exhibited similar choice behavior to the WT to the tested bacteria (Figures 1C-E) regardless of the L. zeae LB1 pretreatment.

To determine which part of the L. zeae LB1 culture attracted C. elegans, L. zeae LB1 cells and culture supernatant were tested individually (Figure 1F). The choice index of L. zeae LB1 culture supernatant against its cells was almost 1 . Similar results were also obtained when both mutants ( $t p h-1$ and cat-2) were examined in the same assay (Figure 1G).

\section{The Potential Involvement of Serotonin and Dopamine in the Resistance of Caenorhabditis elegans to Salmonella Typhimurium DT104 Infection}

The responses of both the WT and mutants of C. elegans to DT104 infection are shown in Figure 2. The WT infected with DT104 had a significantly shorter life span than uninfected worms (feed Escherichia coli OP50 only; $P \leq 0.05$ ). For example, the survival rate of infected WT was $43.33 \pm 6.67 \%$ at the seventh day, while that of uninfected WT was $91.00 \pm 1.51 \%$. Mutants tph-1 and cat- 2 both succumbed faster than the WT after DT104 infection $(P \leq 0.05)$. At the seventh day, $t p h-1$ and cat-2 had a survival rate of $32.22 \pm 5.03 \%$ (Figure 2A) and $30.00 \pm 6.00 \%$ (Figure 2B), respectively.

\section{The Potential Involvement of Serotonin and Dopamine in the Protection From Lactobacillus zeae B1}

The effects of $L$. zeae LB1 on the resistance of C. elegans (both the WT and mutants) to DT104 infection were also investigated. Synchronized L4 stage WT worms were treated with L. zeae LB1 for $18 \mathrm{~h}$ followed by Salmonella Typhimurium DT104 infection for up to 7 days. The results showed that the survival rate of the WT pretreated with L. zeae LB1 was higher than that of the same worms infected with DT104 only, indicating that L. zeae LB1 pretreatment for $18 \mathrm{~h}$ significantly increased the resistance of the WT to $S$. Typhimurium infection $(P \leq 0.05)$ as reported previously (Wang et al., 2011). Pre-exposure to L. zeae LB1 for $18 \mathrm{~h}$ could significantly increase the survival of mutant tph-1 with the level close to the WT, which was significantly higher than that of mutant $t p h-1$ infected with DT104 only $(P \leq 0.05$; Figure 3A). In contrast, $L$. zeae LB1 offered no protection to mutant cat-2, resulting in a survival rate comparable with that of the same mutant infected with DT104 only (Figure 3B). These results suggested that dopamine, but not serotonin, was involved 

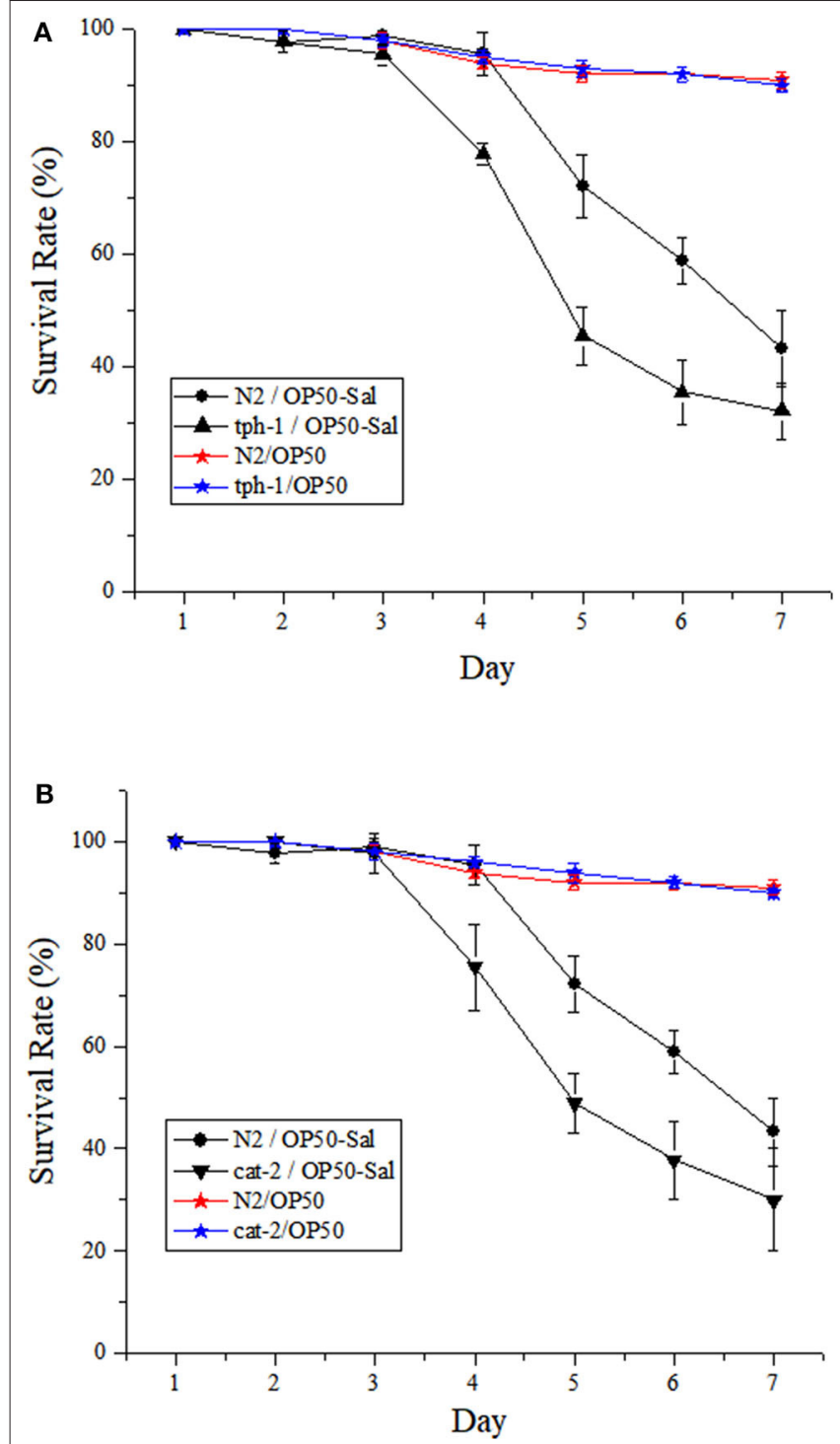

FIGURE 2 | The potential involvement of serotonin and dopamine in the resistance of Caenorhabditis elegans to Salmonella Typhimurium DT104 infection. The mutants are defective in (A) tph-1 or (B) cat-2. N2: the wild type (WT) of C. elegans. N2/OP50, tph-1/OP50, and cat-2/OP50: the WT or each mutant was treated with OP50 only. N2/OP50-Sal, tph-1/OP50-Sal, and cat-2/OP50-Sal: the WT or each mutant was incubated with OP50 first, followed by DT104 infection in the life-span assay. The number of live worms was recorded daily and calculated as follows: survival rate $(\%)=($ live worms/total worms used) $\times 100$. A worm was considered to be dead when it failed to respond to touch. Results are presented as mean \pm S.D. with triplicate measurement.

in the protection offered by L. zeae LB1 to C. elegans against S. Typhimurium DT104 infection.

\section{Supplementation of Dopamine Increased the Resistance of Mutant cat-2 to Salmonella Typhimurium DT104 Infection}

To determine the involvement of dopamine in the host defense to S. Typhimurium DT104 infection, a functional restoring
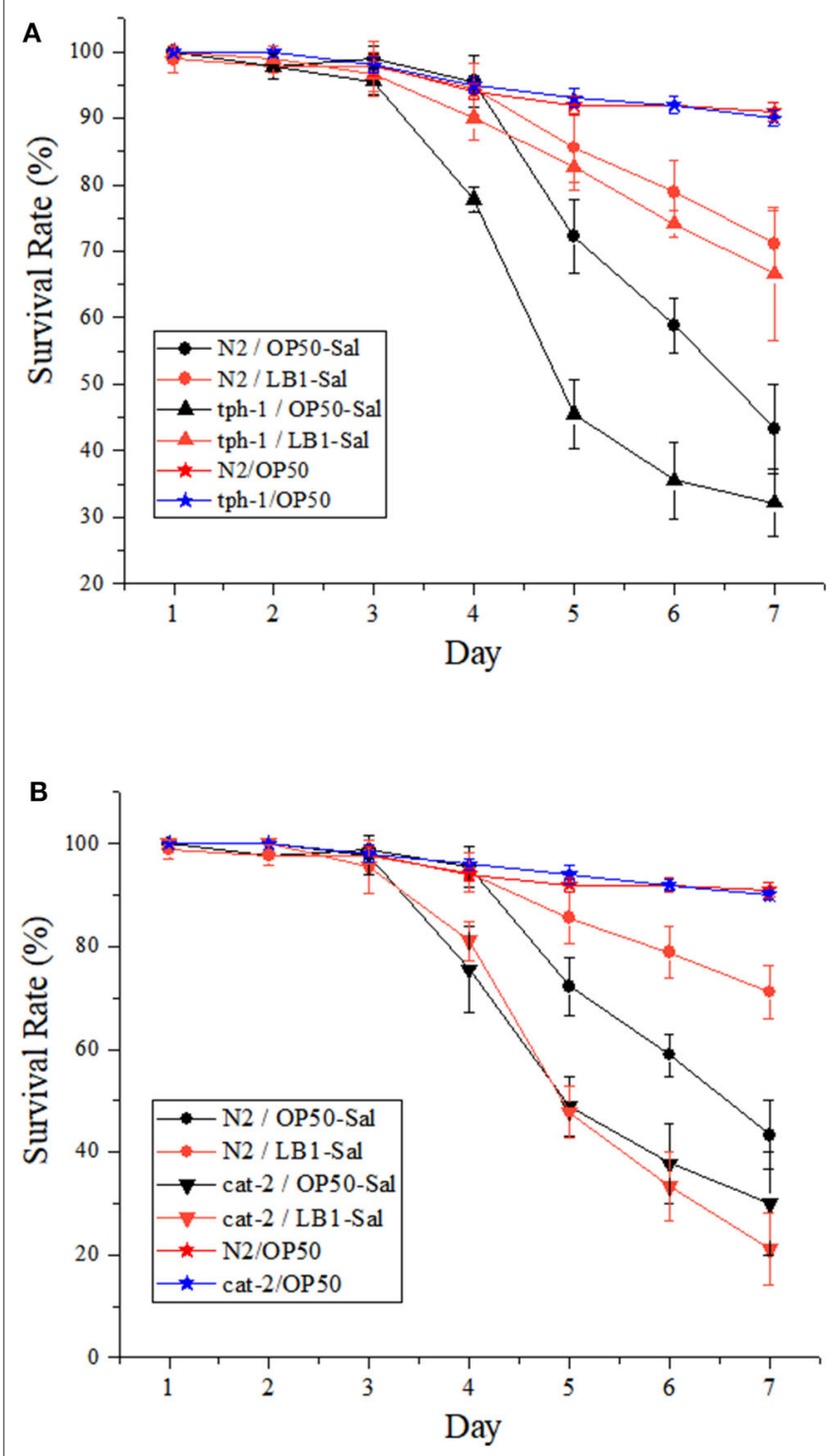

FIGURE 3 | Effect of Lactobacillus zeae LB1 on the resistance of Caenorhabditis elegans mutants to Salmonella Typhimurium DT104 infection. The mutants are defective in (A) tph-1 or (B) cat-2. N2: the wild type (WT) of C. elegans. N2/OP50, tph-1/OP50, and cat-2/OP50: the WT or each mutant was treated with OP50 only. N2/OP50-Sal, tph-1/OP50-Sal, and cat-2/OP50-Sal: the WT or each mutant was incubated with OP50 first, followed by DT104 infection in the life-span assay; N2/LB1-Sal, tph-1/LB1-Sal, and cat-2/LB1-Sal: the WT or each mutant was incubated with L. zeae LB1 first, followed by DT104 infection in the life-span assay. The number of live worms in each group was recorded daily and calculated as follows: survival rate $(\%)=($ live worms/total worms used $) \times 100$. A worm was considered to be dead when it failed to respond to touch. Results are presented as mean \pm S.D. with triplicate measurement.

experiment was conducted by including different concentrations of dopamine $(0,0.25,0.5,0.75$, and $1.5 \mathrm{mM})$ in the life-span assay of $C$. elegans. As shown in Figure 4, mutant cat-2 defective in dopamine production succumbed faster than the WT to $S$. Typhimurium infection $(P \leq 0.05)$, which was in agreement with the observation shown in Figure 2B. The supplementation 


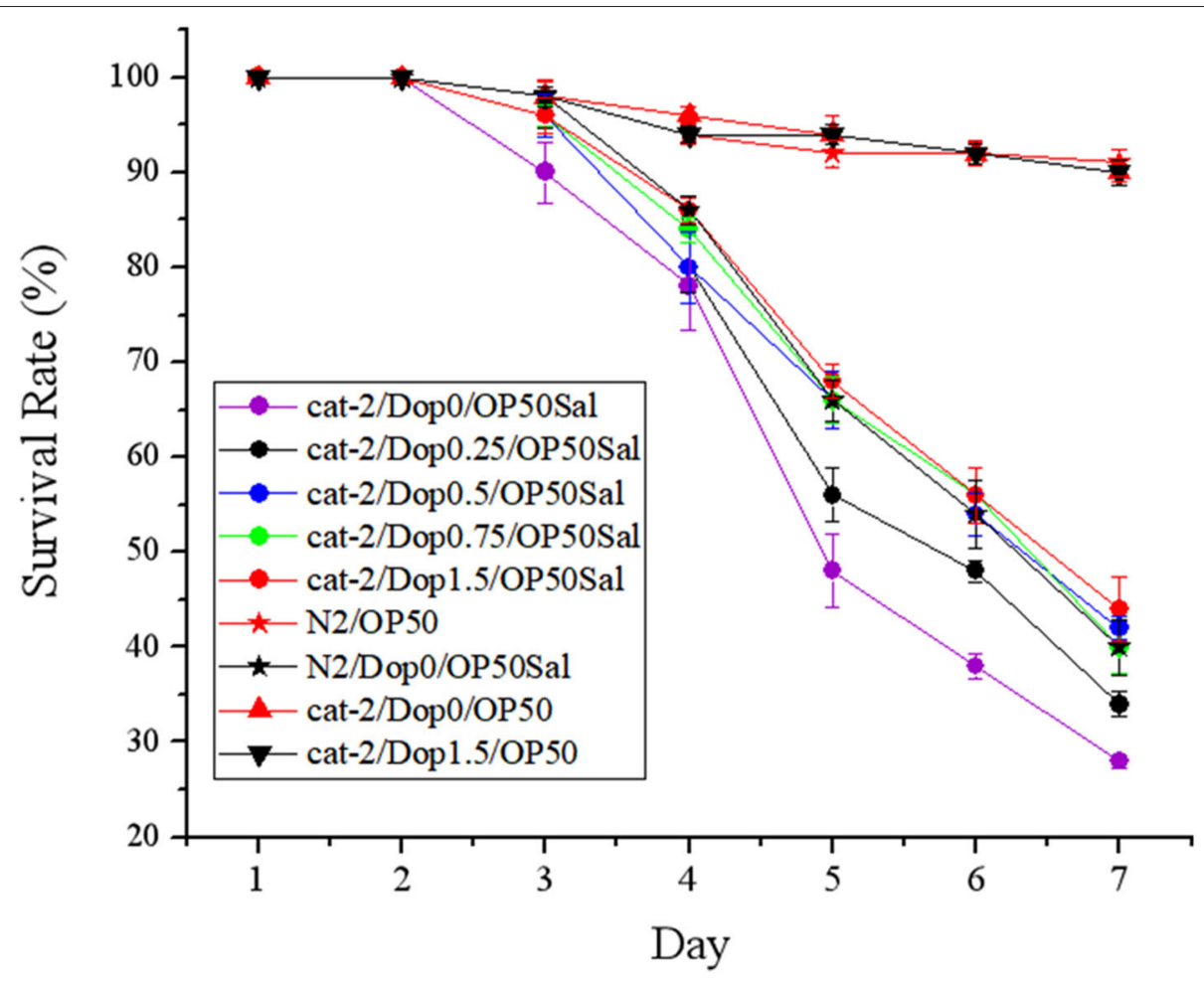

FIGURE 4 | Dopamine involved in the resistance of mutant cat-2 against Salmonella Typhimurium DT104 infection. Synchronized L1 stage worms of mutant cat-2 were treated with various concentration of dopamine $(0,0.25,0.5,0.75$, and $1.5 \mathrm{mM})$ in nematode growth medium (NGM) agar seeded with OP50 until they reached L4 stage. And then the worms were infected with DT104 for 7 days. Then life span was detected. N2: the wild type (WT); cat-2: mutant; Dop0: dopamine at 0 mM; Dop0.25: dopamine at 0.25 mM; Dop0.5: dopamine at 0.5 mM; Dop0.75: dopamine at 0.75 mM; Dop1.5: dopamine at $1.5 \mathrm{mM}$; OP50Sal: treated with Escherichia coli OP50 followed by DT104 infection; OP50: treated with E. coli OP50 only. Wild-type worms (N2) were used as control. The number of live worms in each group was recorded daily and calculated as follows: survival rate $(\%)=$ (live worms/total worms used) $\times 100$. A worm was considered to be dead when it failed to respond to touch. Results are presented as mean \pm S.D. with triplicate measurement.

of dopamine at $0.25 \mathrm{mM}$ significantly increased the resistance of cat- 2 to the infection $(P \leq 0.05)$, in which the survival rate was $34.00 \pm 1.34 \%$ at the seventh day compared with $28.00 \pm$ $0.68 \%$ in the group without dopamine supplementation. When the concentration of dopamine reached $0.5 \mathrm{mM}$ and above (up to $1.5 \mathrm{mM})$, the resistance of cat -2 was further enhanced $(P \leq 0.05)$ with the level similar to the WT infected with DT104 only.

\section{Supplementation of Dopamine Resulted in the Protection From Lactobacillus zeae LB1 to Mutant cat-2 Against Salmonella Typhimurium DT104 Infection}

The effects of supplementation of dopamine on restoring the protection of L. zeae LB1 are given in Figure 5. Again, L. zeae LB1 offered no protection to mutant cat-2 when there was no supplementation of dopamine. However, the protection of L. zeae LB1 was generated by dopamine in a dose-dependent manner ( 0 $1.5 \mathrm{mM})$. In particular, the survival rate $(\sim 70 \%)$ of mutant cat-2 exposed to 0.75 and $1.5 \mathrm{mM}$ of dopamine was comparable with that of the WT without exposure to dopamine when both were subjected to the pretreatment of L. zeae LB1 and DT104 infection. These results indicate that exogenous dopamine at $0.75 \mathrm{mM}$ and above can fully restore the protection of L. zeae LB1 to the nematode mutant against $S$. Typhimurium DT104 infection.

To determine whether dopamine supplementation affected the viability of DT104 and C. elegans as well as the pathogenicity of DT104 in the life-span assay, the assays were performed with the WT nematode that had been either infected or not with DT104 in the absence and presence of dopamine (0.75 and $1.5 \mathrm{mM})$. At both the dopamine concentrations, C. elegans had a similar survival rate to the worms without dopamine treatment regardless if the nematode had been infected with DT104 or not. Similarly, the same level of growth of DT104 in a liquid medium was also observed regardless if dopamine $(0.75$ and $1.5 \mathrm{mM}$ ) was supplemented or not. These results indicate that exogenous dopamine at the tested concentrations had no effects on the viability of both DT 104 and C. elegans as well as the pathogenicity of DT104.

\section{Gene Expression of Mutant cat-2 Responding to Dopamine Supplementation} To determine the cell signaling of mutant cat-2 in response to the supplementation of dopamine in the life-span assay, the gene expression of major components in the p38-MAPK (tir-1, 


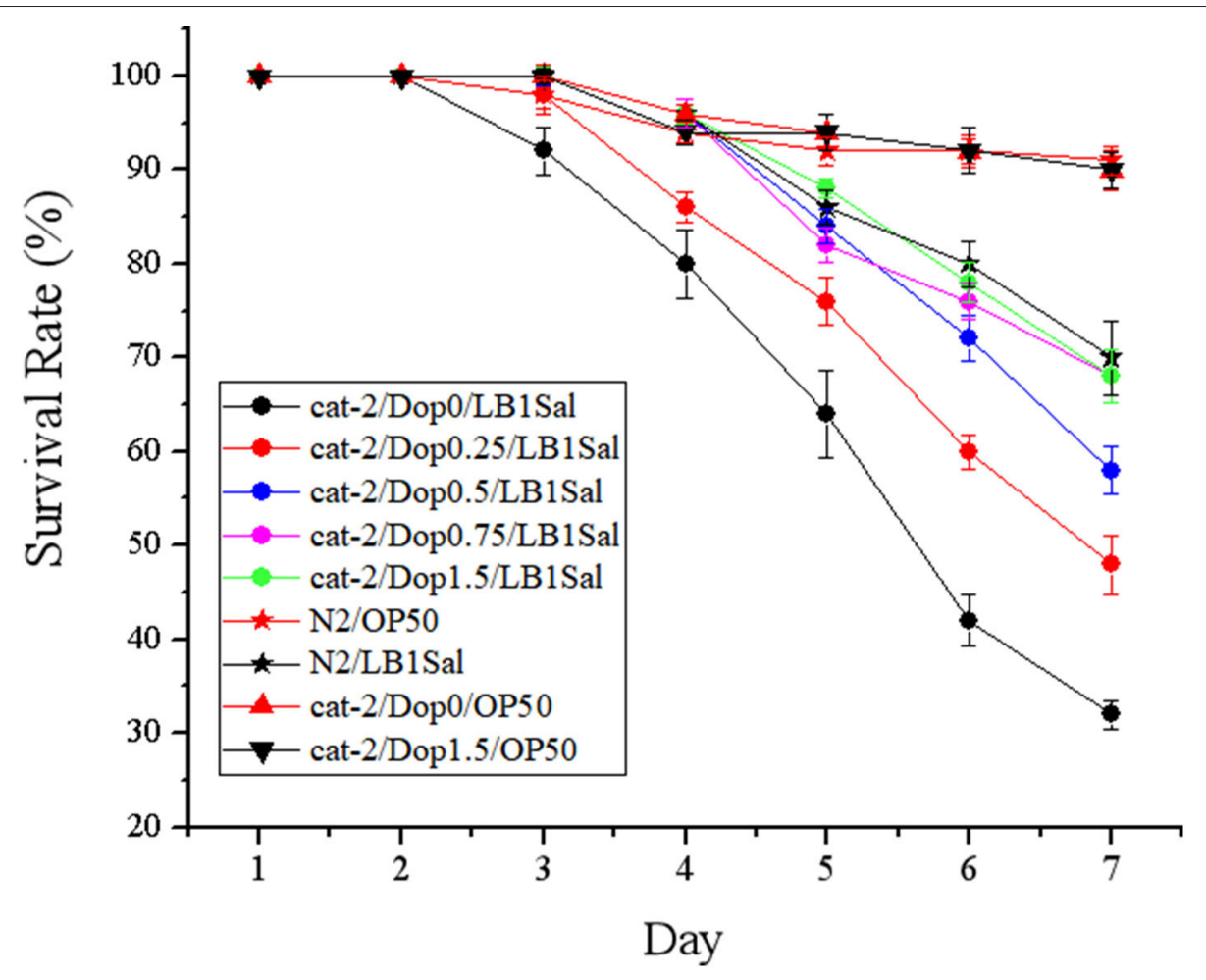

FIGURE 5 | Dopamine resulted in the protection from Lactobacillus zeae LB1 to mutant cat-2 against Salmonella Typhimurium DT104 infection. Synchronized L1 stage worms of mutant cat-2 were treated with various concentration of dopamine $(0,0.25,0.5,0.75$, and $1.5 \mathrm{mM})$ in nematode growth medium (NGM) agar seeded with OP50 until they reached L4 stage. And then the worms were treated with L. zeae LB1 for $18 \mathrm{~h}$ followed by DT104 infection for 7 days. Then life span was detected. N2: the wild type (WT); cat-2: mutant; Dop0: dopamine at 0 mM; Dop0.25: dopamine at $0.25 \mathrm{mM}$; Dop0.5: dopamine at 0.5 mM; Dop0.75: dopamine at $0.75 \mathrm{mM}$; Dop1.5: dopamine at $1.5 \mathrm{mM}$; LB1Sal: treated with L. zeae LB1 for $18 \mathrm{~h}$ followed by DT104 infection for 7 days; OP50: treated with E. coli OP50 only. Wild-type worms (N2) were used as control. The number of live worms in each group was recorded daily and calculated as follows: survival rate (\%) $=$ (live worms/total worms used) $\times 100$. A worm was considered to be dead when it failed to respond to touch. Results are presented as mean \pm S.D. with triplicate measurement.

$n s y-1$, sek-1, and pmk-1) and IGF-1/DAF-16 (age-1 and daf16) pathways, previously identified antimicrobial peptides (lys$7, s p p-1, a b f-2$, clec-85, clec-60, and $a b f-3)$, and other reported defense molecules (sod-3, $d b l-1$, and $s k n-1$ ) was examined with the method described previously (Zhou et al., 2014, 2018). The experiment was carried out in three parallels. In parallel A, gene expression was examined in L4-stage cat-2 worms supplemented without/with $1.5 \mathrm{mM}$ of dopamine. As shown in Figure 6A, when incubated with $E$. coli OP50 alone, several genes in the IGF1/DAF-16 (age-1 and daf-16) and p38-MAPK (pmk-1 and sek1) pathways or for defense functions ( $d b l-1$ and $s p p-1)$ were all down-regulated in mutant cat-2 compared with the WT $(P \leq 0.05)$, and the supplementation of dopamine $(1.5 \mathrm{mM})$ restored their expression back to the level in the WT (value $=1$ ). One exception was the up-regulation of $s k n-1$ expression (involved in defense function) in the mutant, which substantially exceeded the expression level in the WT $(P \leq 0.05)$. However, the supplementation of dopamine $(1.5 \mathrm{mM})$ down-regulated its expression back to the level observed in the WT.

In parallel B, L4-stage cat-2 worms supplemented without/with $1.5 \mathrm{mM}$ of dopamine were incubated with OP50 for $18 \mathrm{~h}$ followed by DT104 infection for $48 \mathrm{~h}$, and the gene expression was then examined. Similarly, age-1, daf-16, pmk-1, sek-1, $d b l-1$, and $s p p-1$ all expressed at low levels in
S. Typhimurium infected mutant cat-2 $(P \leq 0.05)$, and the supplementation of dopamine $(1.5 \mathrm{mM})$ also restored their expression back to the level in the WT (Figure 6B). Again, the expression of $s k n-1$ was up-regulated in the mutant in the absence of dopamine but down-regulated after dopamine supplement $(P \leq 0.05)$.

In parallel C, L4-stage cat-2 worms supplemented without/with $1.5 \mathrm{mM}$ of dopamine were treated with $L$. zeae LB1 for $18 \mathrm{~h}$ followed by DT104 infection for $48 \mathrm{~h}$, and the gene expression was then examined. The six genes (age-1, daf-16, pmk-1, sek-1, dbl-1, and skn-1) demonstrated a similar pattern of gene expression profile (either down-regulation or up-regulation) in the mutant that had been subjected to both $S$. Typhimurium infection and L. zeae LB1 pretreatment before and after the supplementation of dopamine when compared with the WT (Figure 6C). It appears that the mutation in dopamine production induced the immune deficits and life-span shortening in C. elegans, and the supplementation of dopamine could attenuate the mutation effect.

\section{DISCUSSION}

Nematodes possess sensitive olfactory neurons sensing various odors and showing attraction, aversion, and memory of these 
Lit et al.

Neurotransmitters Involved in Probiotic Protection

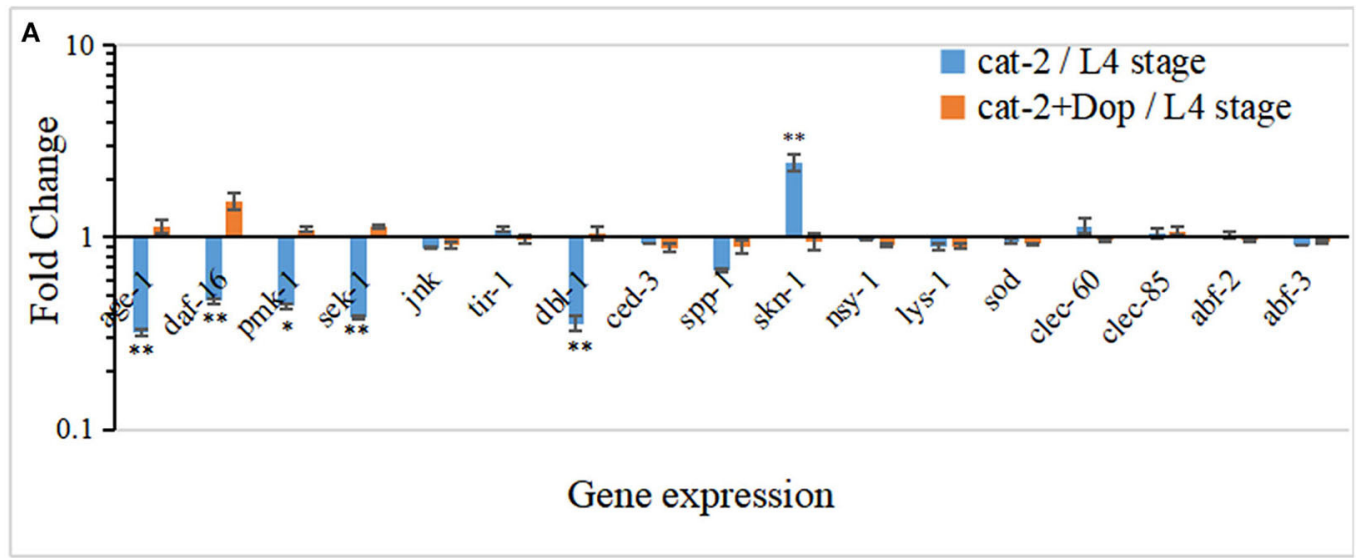

B
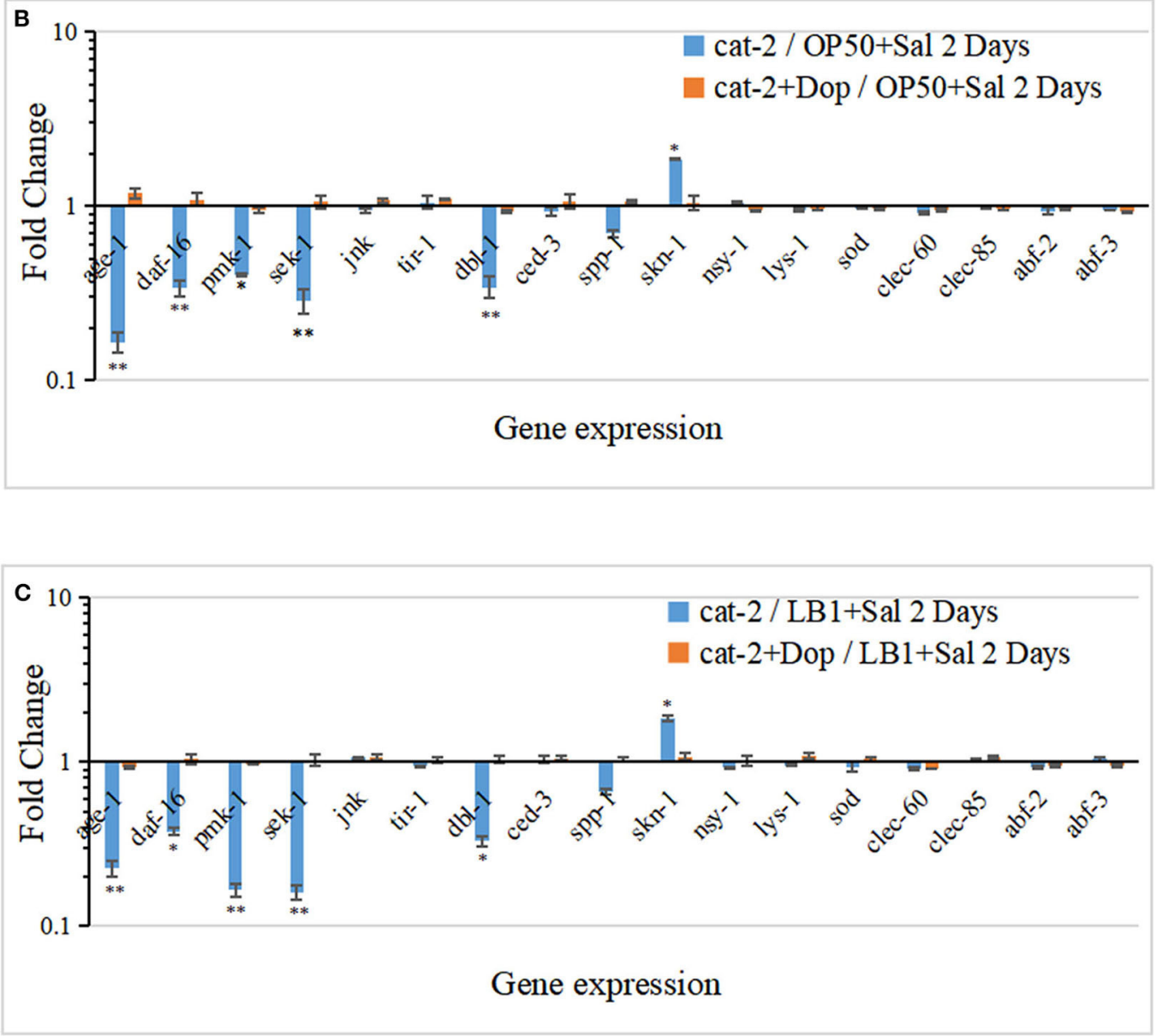

FIGURE 6 | Gene expression response in dopamine-involved protection from Lactobacillus zee LB1 to mutant cat-2 against Salmonella Typhimurium DT104 infection. (A) Gene expression in L4 stage mutant cat-2 treated with or without dopamine. cat-2/L4 stage: L4 stage cat-2 worms; cat-2+Dop/L4 stage: L4 stage cat -2 worms supplemented $1.5 \mathrm{mM}$ of dopamine. (B) Gene expression in mutant cat -2 infected with DT104 treated with or without dopamine. cat-2/OP50+Sal 2 Days: L4 stage cat-2 worms were incubated with OP 50 for $18 \mathrm{~h}$ and then infected with DT104 for 48 h; cat-2+Dop/OP50+Sal 2 Days: L4 stage cat-2 worms were incubated with OP50 for $18 \mathrm{~h}$ and then infected with DT104 for $48 \mathrm{~h}$, and $1.5 \mathrm{mM}$ of dopamine was supplemented in the entire procedure. (C) Gene expression in mutant cat-2 treated with or without dopamine that was also pretreated with L. zee LB1. cat-2/LB1+Sal 2 Days: L4 stage cat-2 worms were pretreated with L. zee LB1 for $18 \mathrm{~h}$ and then infected with DT104 for $48 \mathrm{~h}$; cat-2+Dop/LB1+Sal 2 Days: L4 stage cat-2 worms were pretreated with L. zee LB1 for $18 \mathrm{~h}$ and then infected with DT104 for $48 \mathrm{~h}$, and $1.5 \mathrm{mM}$ of dopamine was supplemented in the entire procedure. $\Delta \mathrm{Ct}$ represents the difference between the Ct value with the primers to a target gene and the Ct value to housekeeping genes. The $\Delta \Delta \mathrm{Ct}$ represents the difference between the $\Delta \mathrm{Ct}$ value of mutant cat-2 group either in the presence or absence of dopamine and the $\Delta$ Ct value of the wild type (WT) control group with the same treatment. The values derived from $2^{-\Delta \Delta C t}$ represent fold changes of mutant cat -2 groups in abundance relative to the WT group. The WT control groups had the $2^{-\Delta \Delta C t}$ value of 1 . Results are presented as mean \pm S.D. with triplicate measurement. ${ }^{*} P \leq 0.05$ for the same gene among different treatments, and ${ }^{* \star} P \leq 0.01$.

Frontiers in Cellular and Infection Microbiology | www.frontiersin.org

9

September 2020 | Volume 10 | Article 554052 
odors (Bargmann et al., 1993). Aversive or attractive behavior may provide a window for protective responses to develop. Previous studies described that bacterial pathogens, such as Serratia marcescens ATCC 13880 and Pseudomonas aeruginosa PA14, can induce aversive olfactory behavior in C. elegans (Ha et al., 2010; Francesco et al., 2016; Jin et al., 2016). However, S. Typhimurium DT104 did not elicit aversive olfactory behavior of the nematode in the current study. Sharma et al. (2019) evaluated chemotactic behavior of C. elegans to 15 probiotic cultures using a binary choice index. Only four tested isolates were preferred by the nematode with 11 isolates less attractive compared with E. coli OP50. In the present study, similar observations were obtained with L. zeae LB1, which was much more attractive to C. elegans than both DT104 and E. coli OP50.

Olfactory learning and "memory" behaviors of C. elegans can be mediated by serotonergic circuits or dopamine signaling (Sawin et al., 2000; Anyanful et al., 2009). While mutation in tph-1 is deficient in tryptophan hydroxylase that is required for biosynthesis of serotonin (Sze et al., 2000), cat-2 encodes tyrosine hydroxylase, the rate-limiting enzyme in dopamine biosynthesis (Lints and Emmons, 1999). The use of both cat-2 mutant and tph-1 mutant was to distinguish their roles and possible mechanisms (Anyanful et al., 2009). In the present study, two mutants defective in either $t p h-1$ or cat-2 exhibited similar choosing behavior to the WT of $C$. elegans, suggesting that nematode preference to L. zeae LB1 did not involve serotonin- or dopamine-mediated motivation or memory behavior.

Bacillus licheniformis was reported to enhance the resistance of C. elegans to the infection of Staphylococcus aureus (Yun et al., 2014), and the effect on the longevity of C. elegans was via host serotonin signaling (Park et al., 2015). In the present study, both tph-1 and cat-2 mutants succumbed faster than the WT to $S$. Typhimurium DT104 infection, suggesting a positive role of both serotonin and dopamine in the nematode defense against the pathogen infection. Furthermore, it has been observed that the resistance of mutant cat-2 to $S$. Typhimurium infection was increased by supplementation of dopamine, but not by pretreatment with $L$. zeae LB1, and that the protection to mutant cat-2 from L. zeae LB1 was also restored by dopamine. These data suggested that dopamine plays an essential role in the resistance of $C$. elegans to $S$. Typhimurium infection, including the protection from $L$. zeae LB1.

Cao and Aballay (2016) reported that dopamine signaling in C. elegans negatively regulated the nematode innate immune response to $P$. aeruginosa infection through a D1-like dopamine receptor, DOP-4, by down-regulating the p38/PMK-1 MAPK pathway. When the nematode was treated with the dopamine antagonist chlorpromazine, it became more resistant to $P$. aeruginosa infection. However, the resistance was significantly reduced by exogenous dopamine. A negative regulation of innate immune response in C. elegans by serotonin was also described by Anderson et al. (2013), in which serotonin signaling limited the rate of pathogen clearance of Microbacterium nematophilum through regulation of G-protein signaling. In the present study, both cat-2 and tph-1 mutants succumbed faster than the WT to $S$. Typhimurium DT104 infection. In addition, exogenous dopamine was able to enhance the resistance of mutant cat-2, although the effect of exogenous serotonin on the resistance of mutant tph-1 was not examined. These data imply that both dopamine and serotonin positively regulate the nematode innate immune response to $S$. Typhimurium DT104 infection, which is obviously different from the observations reported by Cao and Aballay (2016) and by Anderson et al. (2013). In agreement with our findings, a positive regulation of innate immune response by serotonin signaling in $C$. elegans has been documented in response to the infection of $P$. aeruginosa PA14 (Zhang et al., 2005; Gravato-Nobre and Hodgkin, 2010). Worms that lack tph-1 were more susceptible to PA14 than WT animals. It is unknown at present what the potential causes are for the different findings. One possibility could be attributed to the different host responses of $C$. elegans to different bacterial pathogens or even to different isolates within the same species. To clarify the issue, further in-depth and well-controlled comparison studies are required.

It has been shown that neurotransmitters can regulate immune responses. A regulatory axis from the gut microbes to neurotransmitter and then to autoimmune system was proposed in both rodents and humans (Tognini, 2017). Xue et al. (2018) showed that depletion of dopaminergic neurons significantly promoted activation of mice hepatic iNKT cells and augmented concanavalin A-induced liver injury by D1-like receptor-PKA pathway in mice. In the present study, expression of the genes in IGF-1/DAF-16 signaling (age-1 and daf-16) and innate immune signaling pathways ( $p m k-1$ and sek-1) was significantly down-regulated in the mutant defective in cat-2, and supplementation of dopamine to mutant cat-2 restored the expression of these genes to the level in the WT. These results appear to support the notion that dopaminergic signaling has a role in regulating the IGF-1/DAF-16 and innate immune signaling pathways in C. elegans.

The degree of host susceptibility of $C$. elegans to various pathogens or toxins was based on the expression level of genes with a defense function, which was mediated by the IGF/DAF16 or p38-MAP kinase signaling pathways (Troemel et al., 2006). In the present study, the shorter life span and downregulation of defense-related genes in the $S$. Typhimurium infected mutant worms (cat-2) suggest a role of the IGF1/DAF-16 and innate immune signaling pathways mediated by dopamine in the nematode resistance, which is consistent with the report that $C$. elegans may use a neuronal circuit to regulate protective functions via longevity and innate immune signaling pathways to combat bacterial infection when encountered with bacterial pathogens. Similarly, Anyanful et al. (2009) found that EPEC toxins or other pathogens triggered a neuronal circuit mediated by dopaminergic neurons that activated DAF-16 and PMK-1 signaling, which in turn activated other genes to protect $C$. elegans. In addition, Kamaladevi and Balamurugan (2016) reported that Lactobacillus casei triggered a TLR-mediated p38 MAPK pathway to increase host resistance and protect nematodes against pathogen infection. In view of these descriptions, our data support 
the same notion; i.e., the nervous and immune systems can communicate and influence each other in order for the nematode to rapidly and effectively protect themselves from bacterial infection. Given that the signaling pathways are highly conserved from $C$. elegans to humans (Weidhaas et al., 2006), the functions of neurotransmitters reported herein in regulating cell signaling and defense of the nematode may serve as a reference for developing bacterial control strategies in mammalians.

In summary, the present study has demonstrated that both serotonin and dopamine play a positive role in the host defense of $C$. elegans to $S$. Typhimurium infection. The protection offered by $L$. zeae LB1 was not dependent on modifying olfactory preference of the nematode but was mediated by dopamine. In addition, both p38-MAPK and IGF-1/DAF-16 signaling pathways appeared to be involved in the regulation of the protection.

\section{DATA AVAILABILITY STATEMENT}

The raw data supporting the conclusions of this article will be made available by the authors, without undue reservation.

\section{REFERENCES}

Anderson, A., Laurenson-Schafer, H., Partridge, F. A., Hodgkin, J., and McMullan, R. (2013). Serotonergic chemosensory neurons modify the C. elegans immune response by regulating G-protein signaling in epithelial cells. PLoS Pathog. 9:e1003787. doi: 10.1371/journal.ppat.1003787

Anyanful, A., Easley, K. A., Benian, G. M., and Kalman, D. (2009). Conditioning protects C. elegans from lethal effects of enteropathogenic E. coli by activating genes that regulate lifespan and innate immunity. Cell. Host. Microbe 5, 450-462. doi: 10.1016/j.chom.2009.04.012

Bargmann, C. I., Hartwieg, E., and Horvitz, H. R. (1993). Odorant-selective genes and neurons mediate olfaction in C. elegans. Cell 74, 515-527. doi: 10.1016/0092-8674(93)80053-H

Cao, X., and Aballay, A. (2016). Neural inhibition of dopaminergic signaling enhances immunity in a cell-non-autonomous manner. Curr. Biol. 2329-2334. doi: 10.1016/j.cub.2016.06.036

Chambers, J. R., and Gong, J. (2011). The intestinal microbiota and its modulation for Salmonella control in chickens, Food Res. Int. 44, 3149-3159. doi: 10.1016/j.foodres.2011.08.017

Cohen, L. B., and Troemel, E. R. (2015). Microbial pathogenesis and host defense in the nematode C. elegans. Curr. Opin. Microbiol. 23, 94-101. doi: 10.1016/j.mib.2014.11.009

Ermolaeva, M. A., and Schumacher, B. (2014). Insights from the worm: the C. elegans model for innate immunity. Semin. Immunol. 26, 303-309. doi: 10.1016/j.smim.2014.04.005

Ezak, M. J., and Ferkey, D. M. (2010). The C. elegans D2-Like dopamine receptor DOP-3 decreases behavioral sensitivity to the olfactory stimulus 1-Octanol. PLoS ONE 5:e9487. doi: 10.1371/journal.pone.0009487

Ezcurra, M., Tanizawa, Y., Swoboda, P., and Schafer, W. R. (2011). Food sensitizes C. elegans avoidance behaviours through acute dopamine signalling. EMBO J. 30, 1110-1122. doi: $10.1038 /$ emboj.2011.22

Forkus, B., Ritter, S., Vlysidis, M., Geldart, K., and Kaznessis, Y. N. (2017). Antimicrobial probiotics reduce Salmonella enterica in turkey gastrointestinal tracts. Sci Rep. 7:40695. doi: 10.1038/srep40695

Francesco, B., Jadranka, N., Giuseppina, Z., Paolo, B., Di, S. E., and Suhelen, E. (2016). Caenorhabditis elegans employs innate and learned aversion in response to bacterial toxic metabolites tambjamine and violacein. Sci. Rep. 6:29284. doi: $10.1038 /$ srep29284

\section{AUTHOR CONTRIBUTIONS}

XL, LJ, HY, and JG designed the experiments. XL, LJ, and LL performed the research. XL, LJ, LL, HY, and JG analyzed data. SN and MX contributed to discussion and resource provision. XL, LJ, and JG wrote the manuscript. JG and MX conceived the research. All the authors approved the final version of manuscript.

\section{FUNDING}

This work was supported by Agriculture \& Agri-Food Canada through the A-base and Swine Cluster Programs (Project\# J001391 and J-002109), the National Natural Science Foundation of China (81803193), and the Natural Science Foundation of Guangdong Province, China (No. 2018A030310033).

\section{ACKNOWLEDGMENTS}

LJ, XL, and LL were visiting graduate students from Nanchang University, China and were financially supported by the China Scholarship Council through the MOE-AAFC Ph.D. Research Program.

Gravato-Nobre, M. J., and Hodgkin, J. (2010). Caenorhabditis elegans as a model for innate immunity to pathogens. Cell. Microbiol. 7, 741-751. doi: 10.1111/j.1462-5822.2005.00523.x

Gut, A. M., Vasiljevic, T., Yeager, T., and Donkor, O. N. (2018). Salmonella infection - prevention and treatment by antibiotics and probiotic yeasts: a review. Microbiology 164, 1327-1344. doi: 10.1099/mic.0.000709

Ha, H. I., Hendricks, M., Shen, Y., Gabel, C. V., Fang-Yen, C., Qin, Y., et al. (2010). Functional organization of a neural network for aversive olfactory learning in Caenorhabditis elegans. Neuron 68, 1173-1186. doi: 10.1016/j.neuron.2010.11.025

Ikeda,T., Yasui, C., Hoshino, K., Arikawa, K., and Nishikawa, Y. (2007). Influence of lactic acid bacteria on longevity of Caenorhabditis elegans and host defense against Salmonella enterica serovar enteritidis. Appl. Environ. Microb. 73, 6404-6409. doi: 10.1128/AEM.00704-07

Irazoqui, J. E., Urbach, J. M., and Ausubel, F. M. (2010). Evolution of host innate defence: insights from Caenorhabditis elegans and primitive invertebrates. Nat. Rev. Immunol. 10, 47-58. doi: 10.1038/nri2689

Jiang, L., Li, L., Kang, P., Yu, H., Nie, S. P., Xie, M. Y., et al. (2019). Inappropriateness of RNAlater to preserve caenorhabditis elegans for RNA extraction. MethodsX 6, 2460-2467. doi: 10.1016/j.mex.2019.10.015

Jin, J. X., Pokala, N., and Bargmann, C. I. (2016). Distinct circuits for the formation and retrieval of an imprinted olfactory memory. Cell 164, 632-643. doi: 10.1016/j.cell.2016.01.007

Julia, B., Beth, B. F., George, A., Moy, T. I., Ausubel, F. M., and Eleftherios, M. (2007). Antifungal chemical compounds identified using a C. elegans pathogenicity assay. PLoS Pathog. 3:e18. doi: 10.1371/journal.ppat.0030018

Kaletta, T., and Hengartner, M. O. (2006). Finding function in novel targets: C. elegans as a model organism. Nat. Rev. Drug Disco. 5, 387-398. doi: $10.1038 / \mathrm{nrd} 2031$

Kamaladevi, A., and Balamurugan, K. (2016). Lactobacillus casei triggers a TLR mediated RACK-1 dependent p38 MAPK pathway in Caenorhabditis elegans to resist Klebsiella pneumoniae infection. Food Funct. 7, 3211-3223. doi: 10.1039/C6FO00510A

Kamaladevi, A., Ganguli, A., and Balamurugan, K. (2016). Lactobacillus casei stimulates phase-II detoxification system and rescues malathioninduced physiological impairments in Caenorhabditis elegans. Comp Biochem Physiol C Toxicol Pharmacol. 179, 19-28. doi: 10.1016/j.cbpc.2015. 08.004 
Kim, Y., and Mylonakis, E. (2012). Caenorhabditis elegans immune conditioning with the probiotic bacterium Lactobacillus acidophilus NCFM enhances gram-positive immune responses. Infect. Immun. 80, 2500-2508. doi: 10.1128/IAI.06350-11

Lai, W. T., and Huang, F. C. (2019). Probiotics exert reciprocal effects on autophagy and interleukin-1 $\beta$ expression in Salmonella-infected intestinal epithelial cells via autophagy-related 16L1 protein. Benef Microbes 10, 913-922. doi: 10.3920/BM2019.0046

Lints, R., and Emmons, S. W. (1999). Patterning of dopaminergic neurotransmitter identity among Caenorhabditis elegans ray sensory neurons by a TGFbeta family signaling pathway and a Hox gene. Development 126, 5819-5831.

Livak, K. J., and Schmittgen, T. D. (2001). Analysis of relative gene expression data using real-time quantitative PCR and the $2{ }^{-\Delta \Delta C T}$ method. Methods 25, 402-408. doi: 10.1006/meth.2001.1262

Meisel, J. D., and Kim, D. H. (2014). Behavioral avoidance of pathogenic bacteria by Caenorhabditis elegans. Trends Immunol. 35, 465-470. doi: 10.1016/j.it.2014.08.008

Park, M. R., Oh, S., Son, S. J., Park, D. J., Oh, S., Kim, S. H., et al. (2015). Bacillus licheniformis isolated from traditional Korean food resources enhances the longevity of Caenorhabditis elegans through serotonin signaling. J. Agr. Food Chem. 63, 10227-10233. doi: 10.1021/acs.jafc.5b03730

Poppe, C., Smart, N., Khakhria, R., Johnson, W., Spika, J., and Prescott, J. (1998). Salmonella Typhimurium DT104: a virulent and drug-resistant pathogen. Can. Vet. J. 39, 559-565.

Poppe, C., Ziebell, K., Martin, L., and Allen, K. (2002). Diversity in antimicrobial resistance and other characteristics among Salmonella Typhimurium DT104 isolates. Microb. Drug Resist. 8, 107-122. doi: 10.1089/107662902760190653

Qin, J., and Wheeler, A. R. (2007). Maze exploration and learning in C. elegans. Lab Chip. 7, 186-192. doi: 10.1039/B613414A

Sanyal, S., Wintle, R. F., Kindt, K. S., Nuttley,W. M., Arvan, R., Fitzmaurice, P., et al. (2004). Dopamine modulates the plasticity of mechanosensory responses in Caenorhabditis elegans. EMBO J. 23, 473-482. doi: 10.1038/sj.emboj.7600057

Sawin, E. R., Ranganathan, R., and Horvitz, H. R. (2000). C. elegans locomotory rate is modulated by the environment through a dopaminergic pathway and by experience through a serotonergic pathway. Neuron. 26, 619-631. doi: 10.1016/S0896-6273(00)81199-X

Schultz, W. (2016). Dopamine reward prediction-error signalling: a twocomponent response. Nat. Rev. Neurosci. 17, 183-195. doi: 10.1038/nrn.2015.26

Sharma, K., Pooranachithra, M., Balamurugan, K., and Goel, G. (2019). Multivariate analysis of increase in life span of Caenorhabditis elegans through intestinal colonization by indigenous probiotic strains. Probiotics Antimicro. 11, 865-873. doi: 10.1007/s12602-018-9420-0

Stiernagle, T. (1999). Maintenance of C. elegans. Wormbook 11, 1-11.

Sze, J. Y., Victor, M., Loer, C., Shi, Y., and Ruvkun, G. (2000). Food and metabolic signalling defects in a Caenorhabditis elegans serotonin-synthesis mutant. Nature 403, 560-564. doi: 10.1038/35000609

Tognini, P. (2017). Gut microbiota: a potential regulator of neurodevelopment. Front. Cell. Neurosci. 11:25. doi: 10.3389/fncel.2017.00025

Troemel, E. R., Chu, S. W., Reinke, V., Lee, S. S., Ausubel, F. M., and Kim, D. H. (2006). p38 MAPK regulates expression of immune response genes and contributes to longevity in C. elegans. PLoS Genet. 2:e183. doi: 10.1371/journal.pgen.0020183

Visvikis, O., Ihuegbu, N., Labed, S. A., Luhachack, L. G., Alves, A. M. F., Wollenberg, A. C., et al. (2014). Innate host defense requires TFEBMediated transcription of cytoprotective and antimicrobial genes. Immunity. 40, 896-909. doi: 10.1016/j.immuni.2014.05.002

Wang, C., Gong, J., Yu, H., Pacan, J. C., Niu, Z., Si, W., et al. (2011). Use of Caenorhabditis elegans for preselecting Lactobacillus isolates to control Salmonella Typhimurium. J. Food Protect. 74, 86-93. doi: 10.4315/0362-028X.JFP-10-155

Wei, S., Chelliah, R., Rubab, M., Oh, D. H., Uddin, M. J., and Ahn, J. (2019). Bacteriophages as potential tools for detection and control of Salmonella spp. in food systems. Microorganisms 7:570. doi: 10.3390/microorganisms 7110570

Weidhaas, J. B., Eisenmann, D. M., Holub, J. M., and Nallur, S. V. (2006). A Caenorhabditis elegans tissue model of radiation-induced reproductive cell death. Proc. Natl. Acad. Sci U.S.A. 103, 9946-9951. doi: 10.1073 /pnas.0603791103

Xue, R., Zhang, H., Pan, J., Du, Z., Zhou, W., Zhang, Z., et al. (2018). Peripheral dopamine controlled by gut microbes inhibits invariant natural killer $\mathrm{T}$ cellmediated hepatitis. Front. Immuno. 9:2398. doi: 10.3389/fimmu.2018.02398

Yun, H. S., He, J. H., Son, S. J., Park, M. R., Oh, S., Song, M. H., et al. (2014). Bacillus licheniformis isolated from korean traditional food sources enhances the resistance of Caenorhabditis elegans to infection by Staphylococcus aureus. J Microbiol Biotechnol. 24, 1105-1108. doi: 10.4014/jmb.1406. 06008

Zhang, Y., Lu, H., and Cornelia, I. B. (2005). Pathogenic bacteria induce aversive olfactory learning in Caenorhabditis elegans. Nature 438, 179-184. doi: 10.1038/nature04216

Zhou, M., Liu, X., Yu, H., Yin, X., Nie, S., Xie, M., et al. (2018). Cell signaling of Caenorhabditis elegans in response to enterotoxigenic Escherichia coli infection and Lactobacillus zeae protection. Front. Immunol. 9, 1745-1756. doi: 10.3389/fimmu.2018.01745

Zhou, M., Yu, H., Yin, X., Sabour, P. M., Chen, W., and Gong, J. (2014). Lactobacillus zeae protects Caenorhabditis elegans from enterotoxigenic Escherichia coli-caused death by inhibiting enterotoxin gene expression of the pathogen. PLoS ONE. 9:e89004. doi: 10.1371/journal.pone.0089004

Conflict of Interest: The authors declare that the research was conducted in the absence of any commercial or financial relationships that could be construed as a potential conflict of interest.

Copyright (c) 2020 Nie, Xie, and Her Majesty the Queen in Right of Canada, as represented by the Minister of Agriculture and Agri-Food Canada. This is an open-access article distributed under the terms of the Creative Commons Attribution License (CC BY). The use, distribution or reproduction in other forums is permitted, provided the original author(s) and the copyright owner(s) are credited and that the original publication in this journal is cited, in accordance with accepted academic practice. No use, distribution or reproduction is permitted which does not comply with these terms. 